\title{
Teaching
Methods
}

\section{Total Crop Management Increases Undergraduate Student Confidence in Producing Containerized Poinsettias in Greenhouse Production Courses}

\author{
Christopher J. Currey ${ }^{1,4}$ and Roberto G. Lopez ${ }^{2,3}$
}

AdDitional INDEX wORDs. discussion, data collection, decision-making, floriculture, problem solving, instructional scaffolding, reflection

\begin{abstract}
SUMMARY. Total crop management (TCM) is a holistic approach to crop production that integrates data collection and interpretation to facilitate decisions that produce a uniform, high-quality, and marketable crop. Our objective was to determine if integrating TCM into poinsettia (Euphorbia pulcherrima) production experiences at two separate land-grant universities would improve student confidence in greenhouse potted plant production decision-making skills. Students produced containerized poinsettias and collected data on the greenhouse environment [light, temperature, and relative humidity $(\mathrm{RH})]$, plant growth, media properties, irrigation water quality, and pest populations weekly at Purdue University (PU) (2011 and 2013) and Iowa State University (ISU) (2013) or biweekly (2015). Students were provided with selfassessments at the beginning and end of each course with statements about TCM and the various components comprising TCM activities. For nearly every statement at both institutions, self-assessments in confidence and understanding increased on the pre- to postsemester surveys. The systematic data collection combined with discussion and reflection provides an opportunity for peer instruction and learning. We believe TCM increases student confidence in their greenhouse plant production skills.
\end{abstract}

$\mathrm{C}$ ommercial greenhouse producers must understand how plant species and cultivars, the environment (light, temperature, and atmospheric gases), plant culture (irrigation, mineral nutrition, and media), and pests (insects and diseases) affect floriculture crop growth and development (Boodley, 1996; Dole and Wilkins, 2005). Therefore, greenhouse crop production instruction must draw from a wide range of scientific concepts. Applying this broad body of knowledge to successfully solve problems and make decisions to consistently produce high-quality greenhouse crops can be challenging for students.
TCM is a holistic approach to containerized crop production based on integrating data and data collection with critical evaluation (Faust et al., 2000; Gill and Smith-Fiola, 2016). It begins with a regularly monitoring the greenhouse environment, plant growth, media and irrigation water properties, and pest populations and generating quantitative data describing these parameters (Camberato and Lopez, 2011; Currey and Lopez, 201 1; Hutchinson et al., 2011; Lopez and Currey, 2011). Producers may then evaluate the effectiveness of previous management decisions comparing new to previously collected data, as well as using the most current conditions to inform how to proceed with production. Regular monitoring and data collection aids producers in making appropriate management decisions to growing uniform, high-quality, and marketable crops. This approach to containerized crop production closely resembles the roles and responsibilities commercial production managers and head and section growers must assume for successful production.

Floriculture crops for the top 15 producing states were most recently valued at $\$ 4.37$ billion [U.S. Department of Agriculture (USDA), 2016]. Poinsettias are the second-most valuable potted flowering plant, with a wholesale value of nearly $\$ 140$ million for the 32 million units produced in 2015 (USDA, 2016). They are also a model for greenhouse crop production instruction due to their photoperiodic flowering response, variation among bract color and growth vigor, and susceptibility to pests, as well as having well-characterized responses to light, temperature, and mineral nutrients. Additionally, the scale and value of poinsettia production has led to the characterization of these production requirements and the publication of well-defined production guidelines (Dole and Wilkins, 2005; Ecke et al., 2004; Larson, 1992; Nau, 2011).

Experiential education is a technique that enhances student learning by immersing students into theory and practices described in the classroom (Kolb, 2015). Furthermore, experiential education has been shown to increase student confidence in their disciplines, assisting them with the transition from the classroom to internships or careers (Peyre et al., 2006; Wagner et al., 2009). Educators can scaffold their instruction as a means to assist students in developing higherorder critical thinking skills such as analysis, synthesis, and evaluation (Athanassiou et al., 2016). Instructional scaffolding includes: 1) a collaborative interaction between the student and expert, 2) learning that occurs in the learner's zone of proximal development, and 3) gradual removal of support and guidance [the scaffold (Davis, 2015)].

Faust et al. (2000) reported TCM activities with commercial greenhouse poinsettia producers served as an effective educational tool for graduate students. We hypothesized TCM could be used to provide scaffolded 
experiential education for enhancing undergraduate student confidence in greenhouse crop production. The objective of our work was to determine if integrating TCM into greenhouse poinsettia production experiences would improve student confidence in their greenhouse plant production skills.

\section{Methodology}

The TCM activities were integrated into two different courses with greenhouse production emphases and experiences, one at PU (West Lafayette, IN) in 2011 and 2013 and one at ISU (Ames, IA) in 2013 and 2015. At PU, TCM was integrated into HORT 491-Special Assignments in Horticulture, a l-credit course with one 2 -h laboratory every week during the fall semester. There are no prerequisites for HORT 491.

At ISU, TCM was integrated into the laboratory portion of HORT 434Fall Greenhouse Crop Production, a 3 -credit course, with two 50-min lectures and $\mathrm{a} 2 \mathrm{~h}$ and $50 \mathrm{~min}$ laboratory every week. The prerequisites for HORT 434 are HORT 330Herbaceous Plant Identification and HORT 332-Greenhouse Operations and Management.

Students collected data on crop growth, media and irrigation water properties, greenhouse environments, and pests every week in 2011 [PU $(\mathrm{n}=10)$ ] and 2013 [ISU $(\mathrm{n}=$ $10), \mathrm{PU}(\mathrm{n}=6)]$ or biweekly in 2015 [ISU $(\mathrm{n}=11)]$. At PU, students worked in small groups (two to four students) to collect data for four different poinsettia cultivars and the groups rotated across different responsibilities. At ISU, each student performed

\footnotetext{
We gratefully acknowledge Rob Eddy and Peter Lawlor for greenhouse assistance; Garrett Owen for teaching assistance; Plantpeddler and DümmenOrange for plant material; and OHP and Fine Americas for plant growth regulator. We thank Cynthia Haynes and Ann Marie VanDerZanden for thoughtful discussion and input into the manuscript.

The use of trade names in this publication does not imply endorsement by Iowa State, Purdue, or Michigan State Universities of products named nor criticism of similar ones not mentioned.

${ }^{1}$ Department of Horticulture, Iowa State University, 127 Horticulture Hall, Ames, IA 50011

${ }^{2}$ Department of Horticulture and Landscape Architecture, Purdue University, 625 Agriculture Mall Drive, West Lafayette, IN 47907

${ }^{3}$ Current address: Department of Horticulture, Michigan State University, 1066 Bogue Street, East Lansing, MI 48824

${ }^{4}$ Corresponding author. E-mail: ccurrey@iastate.edu.
} doi: 10.21273/HORTTECH03625-16 all TCM responsibilities individually for two different poinsettia cultivars. Although the cultivars varied between institutions and years, a standard red cultivar such as Prestige Red or Freedom Red was always included and the remaining cultivar(s) were selected for their different bract color, response time, and/or vigor.

Light, temperature, and $\mathrm{RH}$ data for the greenhouse environment were recorded daily (Currey and Lopez, 2011). A data logger with a quantum sensor and naturally aspirated thermocouple in a solar radiation shield (WatchDog 2475 Plant Growth Station; Spectrum Technologies, Aurora, IL) recorded daily light integral (DLI), average daily temperature (ADT), difference between the day and night air temperatures, and RH.

Graphical tracking was used to track poinsettia growth and development (Fisher and Heins, 1995). Beginning immediately after plants were pinched, students measured poinsettia plant height and entered means for each cultivar in a graphical tracking program (Ecke Ranch Poinsettias, 2016). Height curves were developed individually for different cultivars and were custom designed using initial starting heights and a final target height of 16 to 18 inches (40.6 to $45.7 \mathrm{~cm})$ (Ecke et al., 2004).

Pour-through (Wright et al., 1990) media tests were performed to collect leachate from growing media. Additionally, samples of clear water and water containing watersoluble fertilizers were collected (Petersen, 1996). The electrical conductivity (EC) and $\mathrm{pH}$ of media leachate and irrigation water were measured with a handheld $\mathrm{pH}$ and EC probe (HI 9813-6N; Hanna Instruments, Woonsocket, RI).

Greenhouse pests were monitored with sticky cards and plant inspections (Gill and Sanderson, 1998; Powell and Lindquist, 1997). Yellow sticky cards were placed among the poinsettias at canopy height and inspected with a hand lens or microscope to determine greenhouse whitefly (Trialeurodes vaporariorum), western flower thrips (Frankliniella occidentalis), and fungus gnat (Bradysia sp.) populations. Cards were replaced after each inspection. Plant foliage and root systems were also monitored for the presence of insect pests or diseases including botrytis (Botrytis cinerea) and pythium (Pythium sp.) and incidences were recorded. Other insect pests and beneficial insects such as green peach aphids (Myzus persicae) and predatory wasps (Encarsia formosa), respectively, were reported if identified. In addition to routine pest inspection, plants displaying signs or symptoms of nutrient or physiological disorder or damage were brought back to the laboratory classroom for discussion.

Once data were collected in the greenhouse, students returned to the laboratory classroom to input data and create graphs. Each class developed target values for plant height, media $\mathrm{pH}$ and $\mathrm{EC}$, and greenhouse DLI and ADT specific to poinsettias using published, recommended values and guidelines (Dole and Wilkins, 2005; Ecke et al., 2004; Gibson et al., 2007; Gill and Smith-Fiola, 2016; Nau, 2011). Discussions followed data entry, graphing, and review and comparison with target values. When values were outside the recommended or target ranges the class discussed interventions and corrective procedures to take. Interventions and corrective actions frequently discussed were common, acceptable practices for containerized poinsettia production (Table 1 ). Although students were unable to participate in corrective procedures such as plant growth regulator, insecticide, and fungicide applications which required pesticide applicator certification, we aimed to focus on activities that students were able to participate in and implement whenever possible.

Questions were designed to quantify student understanding of TCM and the principle aspects involved in using TCM for crop production. Before the first class meeting, each student was provided with an Institutional Review Board-approved, self-assessment with Likert-scale (Likert, 1932 ) responses ( $\mathrm{l}=$ strongly disagree, $2=$ disagree, $3=$ not sure, $4=$ agree, or 5 = strongly agree) to the following statements: 1) I have an understanding of the principles of TCM;2) I can implement the processes involved in TCM to grow greenhouse crops; 3 ) I know how to monitor crop height and make successful management decisions related to crop height control with the data collected; 4) I know how to monitor the greenhouse environment (light, 
Table 1. Total crop management interventions or corrective actions for environmental, plant growth, media leachate, and pest and disease data for producing containerized poinsettias.

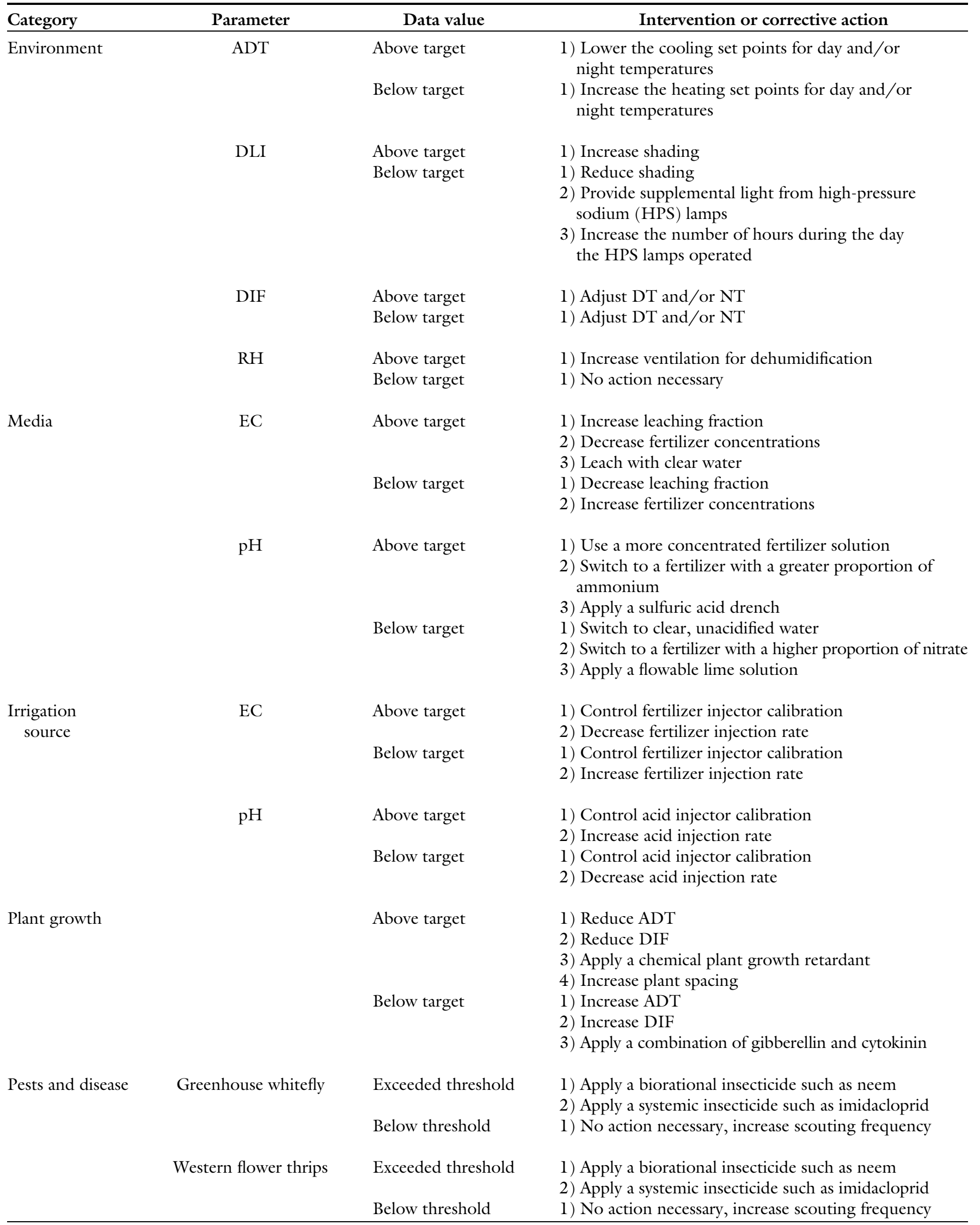

(Continued on next page) 
Table 1. (Continued) Total crop management interventions or corrective actions for environmental, plant growth, media leachate, and pest and disease data for producing containerized poinsettias.

\begin{tabular}{|c|c|c|c|}
\hline Category & Parameter & Data value & Intervention or corrective action \\
\hline & Fungus gnat & Exceeded threshold & $\begin{array}{l}\text { 1) Reduce media moisture content by growing } \\
\text { drier } \\
\text { 2) Apply a biorational insecticide to the media } \\
\text { 3) Apply a synthetic insecticide to the media }\end{array}$ \\
\hline & & Below threshold & 1) No action necessary \\
\hline & & Below threshold & 1) No action necessary \\
\hline & Pythium & $\begin{array}{l}\text { Exceeded threshold } \\
\text { Below threshold }\end{array}$ & $\begin{array}{l}\text { 1) Apply a fungicide to the roots } \\
\text { 1) No action necessary }\end{array}$ \\
\hline
\end{tabular}

Greenhouse environmental parameters, including the average daily temperature (ADT), daily light integral (DLI), difference between the day (DT) and night (NT) air temperatures (DIF), and relative humidity $(\mathrm{RH})$ were measured with an environmental data logger. Media electrical conductivity (EC) and pH were collected using the pourthrough method. Plant growth, determined by height, was measured and plotted in a graphical tracking curve. Insect pest populations including greenhouse whitefly, western flower thrips, and fungus gnats were recorded using sticky card counts and visual inspection and incidences of botrytis and pythium were recorded when observed. The most commonly discussed interventions for values outside recommended ranges were selected from the literature based on ease of implementation primarily by students and secondarily by instructors and greenhouse managers (Dole and Wilkins, 2005; Ecke et al., 2004; Gibson et al., 2007; Gill and Smith-Fiola, 2016; Nau, 2011).

Table 2. Pre- and postcourse self-assessment responses on the understanding and implementation of different principles for total crop management.

\begin{tabular}{|c|c|c|c|}
\hline Question & $\operatorname{Pre}(\mathbf{n}=37)^{\mathbf{z}}$ & Post $(\mathbf{n}=35)^{\mathrm{z}}$ & Sig. ${ }^{y}$ \\
\hline $\begin{array}{l}\text { I know how to monitor crop height and make successful management decisions related } \\
\text { to crop height control with the data collected }\end{array}$ & 3.2 & 4.6 & $* *$ \\
\hline $\begin{array}{l}\text { I know how to monitor the greenhouse environment (light, temperature, etc.) and } \\
\text { make successful management decisions related to environmental management with } \\
\text { the data collected }\end{array}$ & 3.1 & 4.5 & $* * *$ \\
\hline $\begin{array}{l}\text { I know how to monitor for pests and pathogens and can make and implement } \\
\text { successful management decisions relating to pest and pathogen management }\end{array}$ & 3.2 & 4.4 & $* * *$ \\
\hline
\end{tabular}

temperature, etc.) and make successful management decisions related to environmental management with the data collected; 5 ) I know how to monitor the $\mathrm{pH}$ and $\mathrm{EC}$ or irrigation water and growing media and can make and implement successful management decisions related to managing irrigation water and growing media data collected; and 6) I know how to monitor for pests and pathogens and can make and implement successful management decisions relating to pest and pathogen management. The selfassessment was provided to students again at the completion of the semester after the final data were collected and crops were finished. Independent samples $t$ tests were performed on preand postcourse self-assessment data using SPSS 21.0 (IBM Corp., Armonk, NY). Analyses of variance were performed on the effect of location and year on pre- and postcourse assessment responses and, when possible, data were pooled across institution and year for analyses.

\section{Results and discussion}

Agreement with every statement on self-assessments increased over the course of the semester across institutions and years (Tables 2 and 3 ). For statements relating to managing plant height, environmental conditions, and pest and diseases, there were no effects of institution or year and data were pooled across institution and year and confidence increased by 1.2-1.4 over the course of the semester.

Although responses to statements relating to the principles of TCM, implementing the process of TCM, and managing media $\mathrm{pH}$ and EC increased for each institution every year, there institution and year interacted to affect some results (Table 3 ). For statements on the principles and implementation of TCM and related processes, presemester responses increased from 2013 (2.3) to $2015(3.2)$. Alternatively, presemester assessment responses to managing media $\mathrm{pH}$ and $\mathrm{EC}$ decreased between 2013 (3.7) and 2015 (3.2). Though we found variation in responses across institution and year within these statements, given the significant positive increases over every semester for each class for these questions we attribute the significance of these interactions to the small sample sizes.

The results of self-assessments in this study agree with Faust et al. (2000), who reported graduate students participating in TCM training activities increased knowledge and confidence in poinsettia production 
Table 3. Pre- and post-course self-assessment responses on the understanding and implementation of different principles for total crop management (TCM).

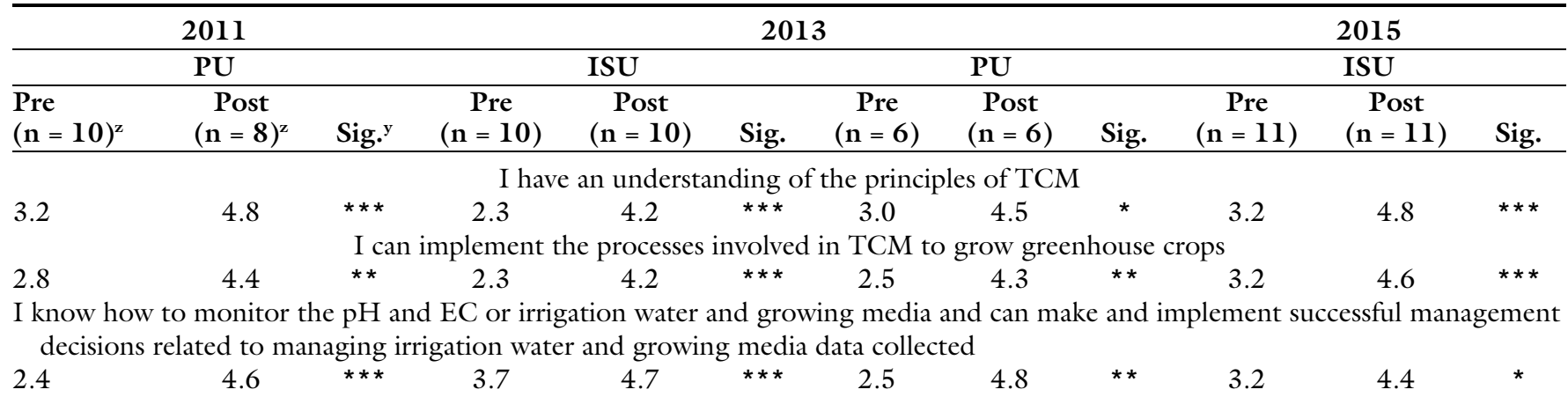

Students enrolled in greenhouse plant production courses at Purdue University [PU (2011, 2013)] and Iowa State University [ISU (2013, 2015)] produced poinsettias and employed routine data collection and discussion to make greenhouse crop production decisions relating to the greenhouse environment, plant growth and height control, water and mineral nutrition, and pest and disease management. Pre- and postcourse self-assessment scores were subject to independent samples $t$ tests and the significance (sig.) is presented.

${ }^{\mathrm{z}}$ Responses on a Likert-scale: $1=$ strongly disagree, $2=$ disagree, $3=$ not sure, $4=$ agree, and $5=$ strongly agree ${ }_{\mathrm{NS}},{ }^{*},{ }^{* *},{ }^{* *}$ Nonsignificant or significant at $P \leq 0.05,0.01$, or 0.001 , respectively.

and extension education as a result of the experience. Although not quantified directly in the self-assessments, we believe the three factors associated with TCM activities that benefitted students were: 1) the regular and systematic data collection, 2) the discussion about what actions to take after reviewing TCM data, and 3 ) the scaffolded learning structure over the course of the semester.

The systematic approach to collecting data on plant growth, the greenhouse environment, media and irrigation solution properties, and pest and diseases provided students with quantitative data to support decision-making based on "real-time" conditions. The regular data collection gave students the opportunity to make production decisions based on quantitative data instead of speculating based solely on visual observations, speculation, or guessing (Kanari and Millar, 2004). In addition to guiding decision-making, this data collection allowed students to reflect on previous production decisions and evaluate effectiveness.

Although not a factor in our pedagogical approach to quantifying effectiveness of TCM, data collection in small groups or individually did not seem to impact the effectiveness of TCM activities as evidenced by the similar trends for both PU (small groups) and ISU (individual) approaches (Table 2). This suggests the structure of TCM can be flexible to accommodate different course schedules and class sizes. As seen in our study, TCM data collection activities were adjusted to accommodate both 50-min and $2 \mathrm{~h}$ and $50 \mathrm{~min}$ laboratory durations. Additionally, biweekly data collection (ISU 2015) appeared sufficient for achieving the objectives of TCM when compared with every week (ISU 2015) (Tables 2 and 3 ) if students had an intensive experience (i.e., collecting all of the data individually). The biweekly approach also left room for additional laboratory activities throughout the semester.

We believe the group discussions were one of the most valuable activities in TCM. The discussions among students and instructors about environment and culture for poinsettia production provided opportunities for peer instruction, use of primary and secondary literature, instructor explanations as needed (Smith et al., 2009, 2011), and student reflection (Nolan, 2008). Peer instruction is an effective way for students to learn from each other and increase understanding of concepts (Smith et al., 2009). In addition to discussing current conditions and making decisions for the following week(s), discussions offered time for reflection among the class. These reflections provided students with opportunities to discuss how previous management decisions earlier in the semester affected crop growth and development. As the semester progressed, previous reflections promoted informed decision-making and increased student engagement in the problem-solving process.

Finally, employment of instructional scaffolding, with respect to containerized plant production concepts, was another component of TCM's success in promoting student confidence. The TCM approach to crop production promoted collaborative interactions among students and instructors due to the frequent engagement in the laboratory setting. Prompts from instructors were provided throughout discussions on an as-needed basis, whether as background information or technical assistance, while questions were also posed to stimulate different lines of inquiry or reasoning. Additionally, the instructors' role in the problemsolving and decision-making discussions diminished as student confidence and knowledge increased as the semester progressed.

To enhance student learning, select poinsettia disorders or production challenges were posed to students in a case study format (Spaw et al., 2008). This allowed us to expand our discussions and broaden the depth of learning beyond a single season and crop and learn about problems beyond those encountered during the class. For instance, bract edge burn was only apparent during one of the four poinsettia seasons. Low light during bract development and coloration reduces transpiration and, therefore, the passive uptake of calcium, which can result in bract edge burn (Ecke et al., 2004). As a result of TCM, student discussion led to the use of supplemental lighting when light levels were decreasing to maintain a target minimum DLI of 10 to $12 \mathrm{~mol} \cdot \mathrm{m}^{-2} \cdot \mathrm{d}^{-1}$ (Nau, 2011), which likely abated bract edge burn. Case studies allowed us to discuss common disorders or challenges such 
as bract edge burn that were absent during the study.

In this study, TCM was used on a single species. However, multiple cultivars varying in vigor and response time (Ecke et al., 2004) were used, each year, providing students with opportunities to observe differences between cultivars (Anderson, 2001a). As stated previously, poinsettia is a good model crop due to the extensive production information available in primary and secondary literature. The framework for much of TCM could be applied to lesser- or unknown crops (Anderson, 200lb); however, the lack of specific information to provide guidelines for students to compare collected data to may pose a challenge. This approach may require more scaffolding from the instructor, but still help students learn how to approach containerized greenhouse crop production.

\section{Conclusions}

Using TCM practices in a greenhouse containerized crop production course enhances student confidence in their ability to apply concepts from collected data to production practices. The principles of TCM can be integrated into any greenhouse production course with the opportunity to grow plants. Instructors may tailor TCM activities to include other activities or focus on other types of greenhouse crops such as annual and perennial bedding plants or hydroponic food crops, but the fundamental structure of TCM provides a successful strategy to teach fundamental concepts and approaches to producing containerized greenhouse crops.

\section{Literature cited}

Anderson, N.O. 2001a. Cultivar trial setup: A case study for potted plant production specialists. HortTechnology 11:481-484.

Anderson, N.O. 2001b. The Floratech dilemma: A case study for potted plant production specialists. HortTechnology 11:477-481.

Athanassiou, N., J.M. McNett, and C. Harvey. 2016. Critical thinking in the management classroom: Bloom's taxonomy as a learning tool. J. Mgt. Educ. 27:533-555.
Boodley, J.W. 1996. The commercial greenhouse. 2nd ed. Delmar, Albany, NY.

Camberato, D.M. and R.G. Lopez. 2011. Basics of monitoring: Media $\mathrm{pH}, \mathrm{EC}$ and water quality. Greenhouse Grower 29 (10):30-32.

Currey, C.J. and R.G. Lopez. 2011. Basics of monitoring: The greenhouse environment. Greenhouse Grower 29 (8):34-40.

Davis, E.A. 2015. Scaffolding learning, p. 845-847. In: R. Gunstone (ed.). Encyclopedia of science education. Springer, New York, NY

Dole, J.M. and H.F. Wilkins. 2005. Floriculture: Principles and species. 2nd ed. Prentice Hall, Upper Saddle River, NJ.

Ecke Ranch Poinsettias. 2016. On target poinsettia height tracking program. 17 Nov. 2016. <www.ecke.com/ontarget/>.

Ecke, P., J.E. Faust, J. Williams, and A. Higgins. 2004. The Ecke poinsettia manual. Ball Publ., Batavia, IL.

Faust, J.E., E. Will, and M. Williams. 2000. Integrating graduate and extension education through total crop management training. HortTechnology 10:378-380.

Fisher, P.R. and R.D. Heins. 1995. A process-control approach to poinsettia height control. HortTechnology 5:5763.

Gibson, J.L., D.S. Pitchay, A.L. WilliamsRhodes, B.E. Whipker, P.V. Nelson, and J.M. Dole. 2007. Nutrient deficiencies of bedding plants: A pictorial guide for identification and correction. Ball Publ., Batavia, IL.

Gill, S.A. and J. Sanderson. 1998. Ball identification guide to greenhouse pests and beneficials. Ball Publ., Batavia, IL.

Gill, S.A. and D. Smith-Fiola. 2016. Total crop management for greenhouse production with an emphasis on integrated pest management and nutrient management. Univ. Maryland Ext. Bul. 363.

Hutchinson, V.A., J.L. Beckerman, C.S Sadof, and R.G. Lopez. 2011. Basics of monitoring: Scouting for pests and pathogens. Greenhouse Grower 29(12):2630 .

Kanari, Z. and R. Millar. 2004. Reasoning from data: How students collect and interpret data in science investigations. J. Res. Sci. Teach. 41:748-769.

Kolb, D.A. 2015. Experiential learning: Experience as the source of learning and development. 2nd ed. Pearson Education, Upper Saddle River, NJ.
Larson, R.A. 1992. Introduction to floriculture. 2nd ed. Academic Press, San Diego, CA.

Likert, R. 1932. A technique for measurement of attitudes. Arch. Psychol. (Frankf.) 140:5-55.

Lopez, R.G. and C.J. Currey. 2011. Basics of monitoring: Graphical tracking. Greenhouse Grower 20(9):22-30.

Nau, J. 2011. Ball redbook. Vol. 2: Crop production. 18th ed. Ball Publ., West Chicago, IL.

Nolan, A. 2008. Encouraging the reflection process in undergraduate teachers using guided reflection. Austral. J. Early Child. 33:31-36.

Petersen, F.H. 1996. Water testing and interpretation, p. 31-50. In: D.W. Reed (ed.). A grower's guide to water, media, and nutrition. Ball Publ., Batavia, IL.

Peyre, S.E., C.G. Peyre, M.E. Sullivan, and S. Towfigh. 2006. A surgical skills elective can improve student confidence prior to internship. J. Surg. Res. 133:11-15.

Powell, C.C. and R.K. Lindquist. 1997. Ball pest and diseases manual. 2nd ed. Ball Publ., Batavia, IL.

Smith, M.K., W.B. Wood, W.K. Adams, C. Wieman, J.K. Knight, N. Guild, and T.T. Su. 2009. Why peer discussion improves student performance on in-class concept questions. Science 323:122-124.

Smith, M.K., W.B. Wood, K. Krauter, and J. K. Knight. 2011. Combining peer discussion with instructor explanation increases student learning from in-class concept questions. CBE Life Sci. Educ. 10:55-63.

Spaw, M., K.A. Williams, L. Hodges, E.T. Paparozzi, and I.L. Mallberg. 2008. A case study to teach the diagnostic process: Determining the cause of chlorosis in a crop of cut dicentra. HortTechnology 18:168-176.

U.S. Department of Agriculture. 2016. Floriculture crops 2015 summary. 29 Aug. 2016. <http://usda.mannlib.cornell. edu/usda/current/FlorCrop/FlorCrop04-26-2016.pdfs.

Wagner, D., M. Bear, and J. Sander. 2009. Turning simulation into reality: Increasing student competence and confidence. J. Nurs. Educ. 48:465-467.

Wright, R.D., K.L. Gruber, and C. Leda. 1990. Medium nutrient extraction with the pour-trough and saturated medium extract procedures for poinsettia. HortScience 6:658-660. 